Research Paper

\title{
Subphthalocyanines as electron mediators in biosensors based on phenol oxidases: Application to the analysis of red wines
}

\author{
R. Gonzalez-Anton ${ }^{\mathrm{a}}$, M.M. Osipova ${ }^{\mathrm{b}}$, C. Garcia-Hernandez ${ }^{\mathrm{a}}$, T.V. Dubinina ${ }^{\mathrm{b}, \mathrm{c}}$, \\ L.G. Tomilova ${ }^{\mathrm{b}, \mathrm{c}}$, C. Garcia-Cabezon ${ }^{\mathrm{a}}$, M.L. Rodriguez-Mendez ${ }^{\mathrm{a}, *}$ \\ a Group UVASENS. Department of Inorganic Chemistry, Escuela de Ingenierías Industriales, Universidad de Valladolid, Paseo del Cauce, 59, 47011 Valladolid, \\ Spain \\ ${ }^{\mathbf{b}}$ Department of Chemistry, M.V. Lomonosov Moscow State University, 1 Leninskie Gory, 119991, Moscow, Russian Federation \\ ${ }^{\mathrm{c}}$ Institute of Physiologically Active Compounds, Russian Academy of Sciences, 1 Severny proezd, 142432 Chernogolovka, Moscow Region, Russian Federation
}

\section{A R T I C L E I N F O}

Article history:

Received 28 June 2017

Received in revised form 27 September 2017

Accepted 27 September 2017

Available online 28 September 2017

\section{Keywords:}

Subphthalocyanine

biosensor

tyrosinase

laccase

bioelectronic tongue

\section{A B S T R A C T}

The electron mediator properties of three subphthalocyanines (SubPcs) [hexa-chloro boron subphthalocyanine (ClSubPc), tri-tert-butyl boron subphthalocyanine ( $t$-BuSubPc) and hexa-phenoxy boron subphthalocyanine (PhOSubPc)] in Tyrosinase and Laccase biosensors (deposited on ITO glass) for the detection of catechol and hydroquinone were evidenced. A particularly remarkable performance was observed in the PhOSubPc-Tyr sensor, which takes account of the $\pi-\pi$ interactions between subphthalocyanine rings and the active sites of the enzymes. Mediated electron transfer between redox enzymes and the ITO electrode improved the limits of detection by one order of magnitude, reaching $10^{-7} \mathrm{~mol} \cdot \mathrm{L}^{-1}$ values. Studies at increasing scan rates confirmed the improvement of the charge transfer rates caused by the presence of the SubPcs. A bioelectronic tongue formed by an array of the SubPc based biosensors has been able to discriminate red wines according to their Total Polyphenol Index.

(C) 2017 Elsevier Ltd. All rights reserved.

\section{Introduction}

Phenol detection plays an important role in the environment and food industry. Conventional methods for phenol detection can be improved by means of electrochemical sensors and sensitive biosensors for the high-throughput screening of phenols in different samples [1]. Enzymatic electrochemical biosensors based on phenol oxidases have shown to be a good alternative for analyzing phenols due to their high sensitivity and selectivity [24].

In electrochemical biosensors, an electron mediator can be used to facilitate the transfer of electrons from the enzyme to the electrode [5].

Phthalocyanines, which are tetrapyrrolic compounds, are efficient electrocatalysts for the non-enzymatic detection of phenols through axial ligand substitution [6] or through $\pi-\pi$ interactions $[7,8]$. They can also be used in combination with other electrocatalytic materials and synergistic effects have been observed [9-12]. In addition, phthalocyanines have been shown to be excellent electron mediators in biosensor functioning

\footnotetext{
* Corresponding author.
}

facilitating the transfer of electrons from the active site of immobilized phenol oxidases to the working electrode surface [13-15]. The wide family of phthalocyanines can offer a variety of derivatives that deserve to be tested as electrocatalytic materials. Subphthalocyanines (SubPcs) consist of three isoindole units with a boron atom at the center and show a three-dimensional delocalized $14 \pi$-electron system. As a family of Pc-related macrocycles, SubPcs possess high thermal stability and high solubility in common organic solvents. The non-planar coneshaped structure of these complexes, as well as the presence of axial ligand prevent aggregation in solvents [16,17]. The structure of SubPcs can be modified in some ways. The halogen atom in the axial position can easily be displaced by nucleophiles $[18,19]$. The variation of peripheral substituents is possible in either the synthesis stage by preparing substituted phthalonitriles [20] or by modifying the subphthalocyanine core [18]. The interesting ringenlargement reaction is unique for the subphthalocyanine macrocycle [21].

In addition, subphthalocyanine analogues with an extended $\pi$-system: (subphthalocyanines [22-24], subazaphenalenephthalocyanines [25] and planar bi- and trinuclear subphthalocyanines $[26,27])$, have been obtained and identified. 
SubPcs were widely investigated as prospective materials in different application fields, among them organic light-emitting diodes [28], organic photovoltaic [29-32] and non-linear optics [33]. Subphthalocyanines have attracted much attention in the field of sensors due to their optic properties, related with an intense $\mathrm{Q}$ absorption band. Colorimetric and fluorometric cyanide sensors based on subphthalocyanines with electron-withdrawing substituents (nitro- and fluorine- groups) were successfully prepared [34]. An ion selective electrode for the salicylate ion, based on phenoxy-substituted subphthalocyanines has recently been described [33].

Besides that, SubPcs have interesting redox properties which are mostly driven by the nature of the macrocyclic aromatic core [16]. According to their fully $\pi$-conjugated macrocyclic structure, and their similarities with other pyrrolic compounds such as phthalocyanines, one could expect subphthalocyanines to show strong electrocatalytic properties towards phenols of interest in the food industry. Likewise, electron mediator properties in biosensors, linked to the pyrrolic structure, can be foreseen. However, such properties should differ from those observed in phthalocyanines due to the different electronic density of the aromatic structure, their conic structure or by the fact that the ligand in the axial position can be displaced by phenols $[18,19]$.

These new sensors with dissimilar electrocatalytic properties, can be applied in the field of multisensor systems (the so-called electronic tongues), where an array of sensors with crossselectivity is coupled to pattern recognition software [35]. Arrays based on phthalocyanines have been successfully used to analyze wines with different qualities or different organoleptic characteristics [36]. The cross-selectivity of the systems could be improved by introducing sensors modified with subphthalocyanines in the array.

In this work, the electron mediator properties of SubPcs in electrochemical biosensors containing Tyrosinase and Laccase, are evaluated. The sensors are prepared on ITO glass and these films are used as the working electrode in voltammetric experiments. Special attention is paid to the influence of the nature of peripheral substituents on sensor properties. For this purpose, the electrocatalytic and electron mediator properties towards phenols of a series of subphthalocyanines (see structures in Fig. 1), possessing electron-withdrawing $(\mathrm{Cl})$, electron-releasing $(t-\mathrm{Bu})$ and $(\mathrm{OPh})$ substituents with intermediate properties are investigated. The sensing properties are tested towards catechol (1,2-dihydroxybenze) and hydroquinone (1,4-dihydroxybenze), two dihydroxybenzene isomers, with many industrial applications which are widespread in the environment [36,37]. Kinetic parameters and detection limits will be calculated and discussed.

Finally, a multisensor system formed by an array of nine sensors and biosensors based on combinations of subphthalocyanines and phenyl oxidases is coupled to a pattern recognition software to obtain a bioelectronic tongue (bioET). The possibility of using such a system to discriminate red wines according to their Total Polyphenol Index, is evaluated.

\section{Material and methods}

All reagents and solvents were purchased from Sigma-Aldrich and used as purchased. Deionized water from MilliQ (resistivity $18.2 \mathrm{M} \Omega \cdot \mathrm{cm}$ ) was used in all electrochemical experiments.

Three subphthalocyanines were included in the study: tri-tertbutyl boron phthalocyanine ( $t$-BuSubPc), hexa-phenoxy boron subphthalocyanine (PhOSubPc) and hexa-chloro boron subphthalocyanine (ClSubPc). $t$-BuSubPc and PhOSubPc were obtained using the previously described approach $[20,38]$. The synthesis of the $\mathrm{ClSubPc}$ is reported here for the first time. Details are given in the following sub-section.

\subsection{Synthesis of hexachlorosubphthalocyanine boron chloride (ClSubPcs)}

A mixture of 1,2-dicyano-4,5-dichlorobenzene (1.0 g, $0.5 \mathrm{mmol})$ and boron trichloride $\left(2.5 \mathrm{~mL} ; 1 \mathrm{~mol} \cdot \mathrm{L}^{-1}\right.$ solution in $\mathrm{CH}_{2} \mathrm{Cl}_{2}$ ) were refluxed in 0 -DCB $(4 \mathrm{~mL})$ under argon. The reaction was controlled with thin-layer chromatography (eluent $\mathrm{C}_{6} \mathrm{H}_{6}$ using Merck Aluminium oxide $\mathrm{F}_{254}$ neutral flexible plates) and absorption spectroscopy. The reaction mixture was cooled to room temperature and $n$-hexane was added. The precipitate was filtered, washed with n-hexane and solved by toluene. Then the solvent was evaporated to give ClSubPc as a purple powder. An additional portion of target complex was obtained by evaporation of the filtrate and subsequent recrystallization from $\mathrm{MeOH}$. The yield of ClSubPc: $(50.0 \mathrm{mg})$. UV-vis $\left(\lambda_{\max }\right.$ (toluene)/nm(I/Imax)): 553 (49\%); 573 (100\%). ${ }^{1} \mathrm{H}$ NMR $\delta \mathrm{H}\left(400.13 \mathrm{MHz}, \mathrm{THF}-\mathrm{d}_{8}\right)(7.99, \mathrm{~s}$, 1H). MS-MALDI-TOF m/z: 637.1871 ([M], 100\%). The molecular mass calculated: 637.3345 . IR spectroscopy (diamond) $1098 \mathrm{~cm}^{-1}$ $(\mathrm{C}-\mathrm{Cl} \mathrm{st}), \quad 738 \mathrm{~cm}^{-1}$ (B-Cl st), $1386-1651 \mathrm{~cm}^{-1}$ ( $\gamma$-pyrrole), $1343 \mathrm{~cm}^{-1}$ (B-N st), $1679 \mathrm{~cm}^{-1}$ (C=N st), $906 \mathrm{~cm}^{-1}$ (1,2,4,5-tetrasubstituted benzene).

\subsection{Preparation of sensors and biosensors}

Sensors based on SubPcs were prepared using a Spin coater model 1H-D7 (Mikasa Co., Tokyo, Japan). ITO glass slides $\left(2 \mathrm{~cm}^{2}\right.$ of surface, surface resistivity $60 \Omega / \mathrm{sq}$ ), provided by DICRYL SA (Spain), were used as a substrate. Prior to the film deposition, substrates were washed in an ultrasonic bath with acetone and rinsed twice with deionized water (MilliQ). Once cleaned, $100 \mu \mathrm{L}$ of $2.5 \cdot 10^{-5} \mathrm{~mol} \cdot \mathrm{L}^{-1}$ toluene solutions were spread onto the substrate and deposited at $700 \mathrm{rpm}$ during 180 seconds (slope of $60 \mathrm{~s}$ ) and dried for 10 minutes in a furnace at $50^{\circ} \mathrm{C}$. The sensors a)

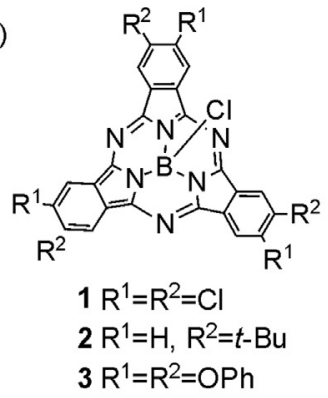

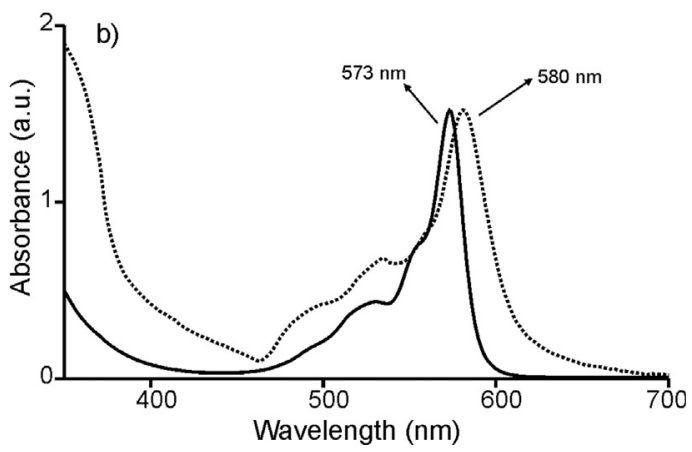

Wavelength (nm)

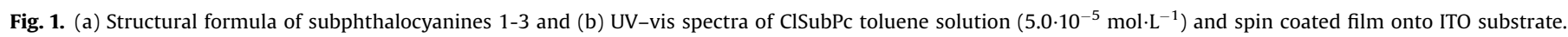


were characterized by UV-vis spectroscopy in a Shimadzu UV2600 model.

Tyrosinase (Tyr) and Laccase (Lac) biosensors were prepared by depositing the corresponding enzyme on top of the SubPc films. Mushroom Tyrosinase (activity of $1000 \mathrm{U} \mathrm{mg}^{-1}$, CAS 9002-10-2) and Trametes Versicolor Laccase (activity of $10 \mathrm{U} \mathrm{mg}^{-1}$, CAS 8049815-3) were purchased from Sigma-Aldrich.

$50 \mu \mathrm{L}$ of solution containing $4.5 \mathrm{mg} \cdot \mathrm{mL}^{-1}$ of the corresponding enzyme (in of a $0.01 \mathrm{~mol} \cdot \mathrm{L}^{-1}$ phosphate buffer; $\mathrm{pH} 7$ ) was spread onto the SubPc films. After drying, the films were immersed for 5 minutes in a $2.5 \%(\mathrm{v} / \mathrm{v})$ glutaraldehyde solution in $0.01 \mathrm{~mol} \cdot \mathrm{L}^{-1}$ phosphate buffer at room temperature. Once dried, the films were immersed for 20 seconds in $0.01 \mathrm{~mol} \cdot \mathrm{L}^{-1}$ phosphate buffer $(\mathrm{pH} 7)$ to remove unbound enzyme from the SubPc film and dried.

\subsection{Electrochemical measurements}

Electrochemical measurements were performed using a potentiostat/galvanostat PGSTAT128 (Autolab Metrohm, Utrecht, Netherlands) and a three-electrode electrochemical cell $(50 \mathrm{~mL})$ using an $\mathrm{Ag} / \mathrm{AgCl} / \mathrm{KClsat}$ as the reference electrode and a platinum sheet $\left(2 \mathrm{~cm}^{2}\right)$ as the counter electrode. Measurements were carried out at room temperature, and non-inert atmosphere. In order to optimize the enzymatic activity, a phosphate buffer $0.01 \mathrm{~mol} \cdot \mathrm{L}^{-1}$ (pH 7) was used as supporting electrolyte.

Kinetic studies were carried out using cyclic voltammetry from $-0.5 \mathrm{~V}$ to $1.2 \mathrm{~V}$, at scan rates from $0.1 \mathrm{~V} \mathrm{~s}^{-1}$ to $1.1 \mathrm{~V} \mathrm{~s}^{-1}$. Detection limits (LDs) were calculated from peak current responses taken from voltammograms registered at different concentrations, following the " $3 \cdot \mathrm{SD} / \mathrm{m}$ " criterion, where " $\mathrm{m}$ " is the slope of the calibration graph and the "SD" was estimated as the standard deviation $(n=5)$ of the blank voltammetric signals.

\subsection{BIoElectronic tongue and wines samples}

Three red wine samples were provided by the "Instituto Tecnológico Agrario de Castilla y León (ITACyL)", located in Valladolid (Spain). Wines were elaborated from the same variety of grape (Tempranillo) but differed in the Total Polyphenol Index (TPI). Wine 1 (TPI = 76.7), wine 2 (TPI = 75.1) and wine 3 (TPI = 58.9).

An array of nine sensors ( $t$-BuSubPc, PhOSubPc, ClSubPc and the corresponding Tyrosinase and Laccase biosensors) was immersed in three wine samples diluted $1: 2$ in phosphate buffer $0.01 \mathrm{~mol} \cdot \mathrm{L}^{-1}$. Voltammograms were registered from $-0.5 \mathrm{~V}$ to $1.2 \mathrm{~V}$ at a scan rate of $0.1 \mathrm{~V} . \mathrm{s}^{-1}$. Five repetitions per sample were measured. Voltammograms were pre-processed with a data reduction technique based on 'kernels' [39]. Using this method, voltammograms were "sliced" into 10 variables that were used as the input for statistical analysis.

The statistical analysis was performed by using Matlab v2014b (The Mathworks Inc., Natick, MA, USA). Principal Component Analysis (PCA) was used to evaluate the discrimination capability of the electronic tongue.

\section{Results and discussion}

The UV-vis spectra of the $5.0 \cdot 10^{-5} \mathrm{~mol} \cdot \mathrm{L}^{-1}$ toluene solution of SubPcs under study showed the characteristic features of these 14 $\pi$-electron conjugated macrocyclic compounds. The spectra showed a strong $\mathrm{Q}$ band that has been assigned to $\pi-\pi^{*}$ transitions [40]. The Q band of the SubPcs shifted to lower wavelengths in the presence of electron donor groups: $t$-BuSubPc $(568 \mathrm{~nm})<$ PhOSubPc $(572 \mathrm{~nm})<$ ClSubPc $(573 \mathrm{~nm})$. In any case, wavelengths were shorter than the typical 650-670 nm observed in phthalocyanines, which are similar systems with an extended aromaticity and is due to the non-planar shape of SubPcs. UV-vis spectra of the spin- coated films were similar to those of toluene solutions, but a bathochromic shift of the $Q$ band was observed in solid films. This red shift is illustrated in Fig. 1. It can be explained using the exciton theory [41], which indicates the formation of $J$-aggregates produced by intermolecular interactions between the aromatic rings and can be related to a molecular core arrangement in stacks.

The redox properties of SubPc spin-coated films in phosphate buffer ( $\mathrm{pH} 7$ ) showed both oxidative and reductive peaks corresponding to the one-electron process at around 0.6 and $0.1 \mathrm{~V}$, respectively. Peaks were quasi-reversible with high separation between the anodic and cathodic waves (ca. $0.5 \mathrm{~V}$ ) which is typical of reversible redox processes in thin solid films. This result is in good agreement with the redox behavior already described for SubPcs in organic solvents [40]; although, obviously, peak positions are modified by the conditions in which electrochemistry is carried out and by peripheral substituents. In our case, oxidation was only slightly affected by the electron donor or acceptor capability of the peripheral substituents. The oxidation potentials were $t$-BuSubPc $(0.53 \mathrm{~V})<\operatorname{PhOSubPc}(0.55 \mathrm{~V})<\mathrm{ClSubPc}(0.60 \mathrm{~V})$. Reduction followed the opposite trend and the ClSubPc reduction peak was $0.2 \mathrm{~V}$ anodically shifted in comparison with the $t$ BuSubPc. Reduction potentials were ClSubPc $(-0.05 \mathrm{~V})<$ PhOSubPc $(0.05 \mathrm{~V})<t$-BuSubPc $(0.15 \mathrm{~V})$.

When the electrode modified with ClSubPc was immersed in catechol $\left(10^{-4} \mathrm{~mol} \cdot \mathrm{L}^{-1}\right.$ in phosphate buffer, $\mathrm{pH}$ 7) (Fig. 2), the redox process corresponding to the oxidation $(0.9 \mathrm{~V})$ reduction $(-0.1 \mathrm{~V})$ of catechol was observed. The intensity was higher than the signal obtained using a bare ITO glass. However, the oxidation/reduction of the ClSubPc was no longer observed. This can be explained by the fact that the ligand in the axial position can be displaced by phenols $[18,19]$. The electrocatalytic effect was only observed in CISubPc, but when SubPc was substituted with electron donor peripheral groups, the electrocatalytic effect was no longer observed. In fact, PhOSubPc completely blocked the transfer of electrons from catechol to the electrode. Similar responses were observed when electrodes were immersed in hydroquinone, an isomer of catechol.

The detection of di-phenols can be improved by using biosensors containing phenol oxidases in the presence of electron mediators. Tyrosinase (Tyr) catalyzes the oxidation of monophenols and 0 -diphenols to the corresponding quinone. Laccase (Lac) catalyzes the oxidation of a larger variety of substituted mono- and poly-phenols, forming radicals which are converted to quinones in the second stage of oxidation [41-43].

The electron mediator properties of SubPcs were evaluated by analyzing the electrochemical reaction of films modified with Tyrosinase (SubPc-Tyr) or Laccase (SubPc-Lac) in the presence of

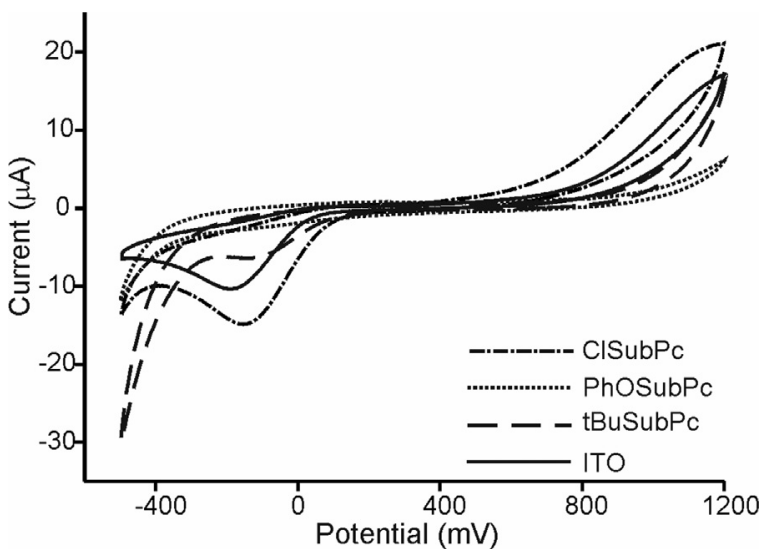

Fig. 2. CV of SubPc spin-coated films immersed in catechol $10^{-4} \mathrm{~mol} \cdot \mathrm{L}^{-1}$ in phosphate buffer $0.01 \mathrm{~mol} \cdot \mathrm{L}^{-1}, \mathrm{pH} 7$. 
catechol and hydroquinone respectively. The electrochemical responses were characterized by an intense peak at ca. $-0.2 \mathrm{~V}$ corresponding to the reduction of the $o$-quinone to catechol.

As observed in Fig. 3, in all three SubPc-enz sensors, the intensity of the signals associated with the electrochemical enzymatic reduction at $-0.3 \mathrm{~V}$ was clearly increased according to the following sequence: $t$-BuSubPc-Tyr $<$ ClSubPc-Tyr $<$ PhOSubPc-Tyr. The stronger electron mediator effect was observed in PhOSubPc-Tyr (from $-15 \mu \mathrm{A}$ using Tyrosinase in the absence of an electron mediator to $-65 \mu \mathrm{A}$ using PhOSubPc as the electron mediator). According to this, the electron mediator properties are not related to the electron-donor or electron-attractor properties of the peripheral substituents. Instead, they seem to be linked to $\pi-\pi$ interactions enabled by the phenoxy groups that facilitate the interaction between the active site of the enzyme, the subphthalocyanine and the catechol aromatic rings. Similar effects have already been described in bisphthalocyanine-Tyr sensors $[13,44]$. The electron mediator properties of SubPcs in biosensors modified with Laccase and exposed to hydroquinone were similar, and the stronger effect was also found in the PhOSubPc-Lac sensor (intensity increased from $-35 \mu \mathrm{A}$ in Laccase biosensors without an electron mediator, to $-53 \mu \mathrm{A}$ in the presence of PhOSubPc). These results demonstrate the strong electron mediator properties shown by the SubPcs, and in particular by the phenoxy substituted PhOSubPc.

The limits of detection $\left(\mathrm{LD}_{\mathrm{c}}\right)$ were calculated from the responses of the Tyr and SubPc-Tyr, to catechol solutions with concentrations ranging from $2.0 \cdot 10^{-5} \mathrm{~mol} \cdot \mathrm{L}^{-1}$ to $5.0 \cdot 10^{-7} \mathrm{~mol} \cdot \mathrm{L}^{-1}$ (supporting electrolyte phosphate buffer $0.01 \mathrm{~mol} \cdot \mathrm{L}^{-1}, \mathrm{pH} 7$ ). Similar experiments were carried out using Lac and SubPc-Lac biosensors immersed in hydroquinone solutions. Calibration curves were used to calculate the sensitivity, the limit of detection (using the $3 \cdot \mathrm{SD} / \mathrm{m}$ criterion) and to establish the linear range (Table 1 ).

In the absence of an electron mediator, the Tyr and Lac sensors showed LDs close to $10^{-6} \mathrm{~mol} \cdot \mathrm{L}^{-1}$. The presence of ClSubPc and PhOSubPc increased the intensity of the peaks and improved the LDs by almost one order of magnitude reaching $10^{-7} \mathrm{~mol} \cdot \mathrm{L}^{-1}$ values. It is particularly worth noting the performance obtained in the PhOSubPc-Tyr sensor, where the lowest LDs and the highest sensitivities were obtained. Taking into account the fact that the trend in electron donor capability (and hence in the redox potentials) of the subphthalocyanines studied is $t$-BuSubPc $<$ PhOSubPc $<$ ClSubPc, we can conclude that other effects must be taken into account to explain the electron mediator effects. The existence of $\pi-\pi$ interactions between the SubPcs and the active sites of the enzymes, similar to those already described between phthalocyanines and phenol oxidases, must be considered as the main mechanism participating in the electron transfer process [13].

The limits of detection reported here are of the same order of magnitude as those reported for sensors and biosensors using metallophthalocyanines and bisphthalocyanines (Table 2).

In order to obtain information about the rate-determining step, voltammograms were obtained at increasing scan rates from 0.1 to $1.1 \mathrm{~V} \mathrm{~s}^{-1}$ in $10^{-4} \mathrm{~mol} \cdot \mathrm{L}^{-1}$ solutions of catechol and hydroquinone (in phosphate buffer $0.01 \mathrm{~mol} \cdot \mathrm{L}^{-1}, \mathrm{pH} 7$ ). The cathodic peaks corresponding to the reduction of $o$-quinone at ca. $-0.5 \mathrm{~V}$ progressively increased their intensity with the scan rate. Simultaneously, peak positions shifted to more negative values (Fig. 4a).

A linear relationship was observed between the intensity of the cathodic peak $\left(\mathrm{I}_{\mathrm{c}}\right)$ and the square root of the scan rate $\left(\boldsymbol{v}^{1 /}\right.$ ${ }^{2}$ ). This suggests the involvement of a kinetic limitation in the redox process. However, a representation between $I_{c}$ and the scan rate also gave a linear correlation, suggesting that the limiting step is the electron transfer of the adsorbed species (Table 3). The relationship between the intensity of the cathodic peak and the scan rate was further analyzed by the representing the $\mathrm{I}_{\mathrm{c}} / v^{1 / 2} v s$. the scan rate. This representation can be used to distinguish between different electrode processes in more detail [51]. If an electrode process is diffusion controlled, the current function $I_{c} / v^{1 / 2}$ is independent from the scan rate (Fig. 4b). In contrast, if a redox process is controlled by charge transfer (as predicted theoretically for a surface-immobilized redox species), the $I_{c} / v^{1 / 2}$ ratio will increase with the scan rate. In our case, we observed that at scan rates lower than 0.20 $\mathrm{V} \cdot \mathrm{s}^{-1}$, the relation $\mathrm{I}_{\mathrm{c}} / v^{1 / 2}$ increased linearly with the sweep rate, but over $0.20 \mathrm{~V} \cdot \mathrm{s}^{-1}$ it became independent of the scan rate and appeared as a plateau. According to this, it can be concluded that the redox processes observed in SubPc-enz biosensors are charge transfer limited below $0.20 \mathrm{~V} \cdot \mathrm{s}^{-1}$ and diffusion controlled over $0.20 \mathrm{~V} \cdot \mathrm{s}^{-1}$.

Laviron's equation (Eq. (1)), can be used to calculate the charge transfer coefficient $\alpha$ for the electron transfer between the electrode and the surface confined redox couple [52,53].

$\mathrm{E}_{\mathrm{c}}=\mathrm{E}^{0}-\frac{2.3 \cdot \mathrm{R} \cdot \mathrm{T}}{\alpha \cdot \mathrm{n} \cdot \mathrm{F}} \log v$

where $E_{c}$ is the cathodic peak potential, $E^{O}$ is a constant that includes the formal standard potential, $\alpha$ is the charge transfer coefficient, $v$ is the scan rate (expressed in $\mathrm{V} \cdot \mathrm{s}^{-1}$ ), $n$ is the number of electrons involved in the process, $R$ is the ideal gas constant
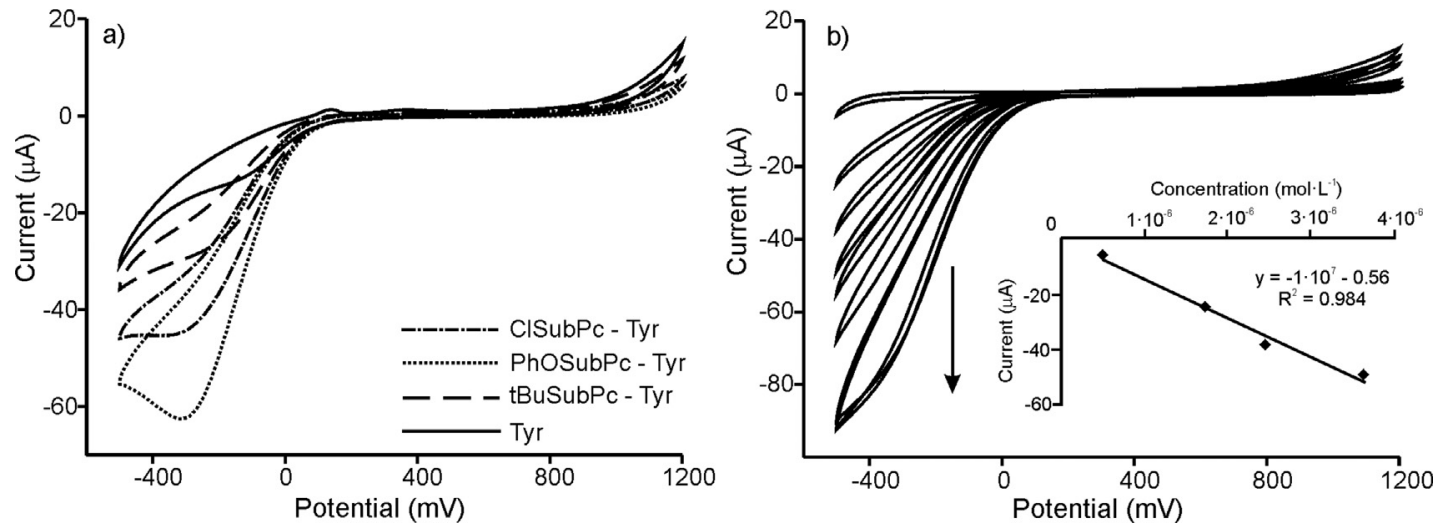

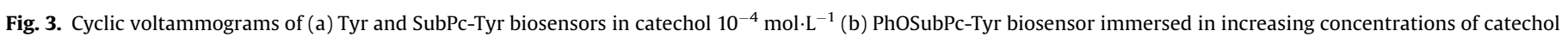

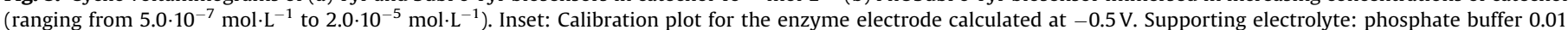
$\mathrm{mol} \cdot \mathrm{L}^{-1}$, $\mathrm{pH} 7$. 
Table 1

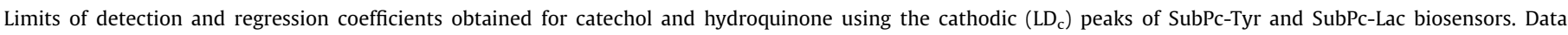
corresponding to Tyr and Lac biosensors in the absence of an electron mediator are also shown.

\begin{tabular}{|c|c|c|c|c|}
\hline \multicolumn{5}{|l|}{ Catechol } \\
\hline \multirow[b]{2}{*}{ Biosensor } & \multicolumn{3}{|l|}{$\mathrm{I}_{\mathrm{c}}(\mu \mathrm{A})$ vs. $\mathrm{C}\left(\mathrm{mol} \cdot \mathrm{L}^{-1}\right)$} & \multirow[b]{2}{*}{$\mathrm{LD}_{\mathrm{c}}\left(\mathrm{mol} \cdot \mathrm{L}^{-1}\right)$} \\
\hline & Linear Range $\left(\mathrm{mol} \cdot \mathrm{L}^{-1}\right)$ & $\mathrm{R}^{2}$ & Sensitivity $\left(\mu \mathrm{A} \cdot \mathrm{M}^{-1}\right)$ & \\
\hline Tyr & $5 \cdot 10^{-7}-2 \cdot 10^{-5}$ & 0.998 & $-9 \cdot 10^{5}$ & $2.16 \cdot 10^{-6}$ \\
\hline ClSubPc-Tyr & $5 \cdot 10^{-7}-2 \cdot 10^{-5}$ & 0.989 & $-1 \cdot 10^{6}$ & $7.57 \cdot 10^{-7}$ \\
\hline PhOSubPc-Tyr & $5 \cdot 10^{-7}-4 \cdot 10^{-6}$ & 0.984 & $-1 \cdot 10^{7}$ & $1.01 \cdot 10^{-7}$ \\
\hline$t$-BuSubPc-Tyr & $7 \cdot 10^{-6}-2 \cdot 10^{-5}$ & 0.995 & $-5 \cdot 10^{5}$ & $2.10 \cdot 10^{-7}$ \\
\hline \multicolumn{5}{|l|}{ Hydroquinone } \\
\hline & \multicolumn{3}{|l|}{$\mathrm{I}_{\mathrm{c}}(\mu \mathrm{A})$ vs. $\mathrm{C}\left(\mathrm{mol} \cdot \mathrm{L}^{-1}\right)$} & \multirow[b]{2}{*}{$\mathrm{LD}_{\mathrm{c}}\left(\mathrm{mol} \cdot \mathrm{L}^{-1}\right)$} \\
\hline Biosensor & Linear Range $\left(\mathrm{mol} \cdot \mathrm{L}^{-1}\right)$ & $\mathrm{R}^{2}$ & Sensitivity $\left(\mu \mathrm{A} \cdot \mathrm{M}^{-1}\right)$ & \\
\hline Lac & $5 \cdot 10^{-7}-2 \cdot 10^{-5}$ & 0.998 & $-4 \cdot 10^{5}$ & $1.66 \cdot 10^{-6}$ \\
\hline ClSubPc-Lac & $5 \cdot 10^{-7}-2 \cdot 10^{-5}$ & 0.994 & $-6 \cdot 10^{5}$ & $1.69 \cdot 10^{-7}$ \\
\hline PhOSubPc-Lac & $5 \cdot 10^{-7}-2 \cdot 10^{-5}$ & 0.976 & $-4 \cdot 10^{5}$ & $1.55 \cdot 10^{-7}$ \\
\hline$t$-BuSubPc-Lac & $5 \cdot 10^{-6}-2 \cdot 10^{-5}$ & 0.999 & $-4 \cdot 10^{5}$ & $4.85 \cdot 10^{-7}$ \\
\hline
\end{tabular}

Table 2

Limits of detection for phthalocyanine-based sensors dedicated to the detection of catechol and hydroquinone taken from the literature.

\begin{tabular}{|c|c|c|c|}
\hline Phthalocyanine & LD Catechol $\left(\mathrm{mol} \cdot \mathrm{L}^{-1}\right)$ & LD Hydroquinone $\left(\mathrm{mol} \cdot \mathrm{L}^{-1}\right)$ & Reference \\
\hline CoPc & $3.40 \cdot 10^{-7}$ & $3.38 \cdot 10^{-7}$ & [45] \\
\hline FeTsPc & $1.76 \cdot 10^{-7}$ & - & [46] \\
\hline $\mathrm{LuPc}_{2}$ & $1.00 \cdot 10^{-6}$ & - & [47] \\
\hline $\mathrm{MnPc}$ & $9.60 \cdot 10^{-5}$ & $4.80 \cdot 10^{-5}$ & [48] \\
\hline $\mathrm{LuPc}_{2}$ & $8.00 \cdot 10^{-6}$ & & [8] \\
\hline $\mathrm{CoPc}$ & $1.66 \cdot 10^{-6}$ & - & [49] \\
\hline FePc & $4.30 \cdot 10^{-7}$ & - & [50] \\
\hline $\mathrm{LuPc}_{2}$ & - & $3.34 \cdot 10^{-7}$ & [50] \\
\hline
\end{tabular}
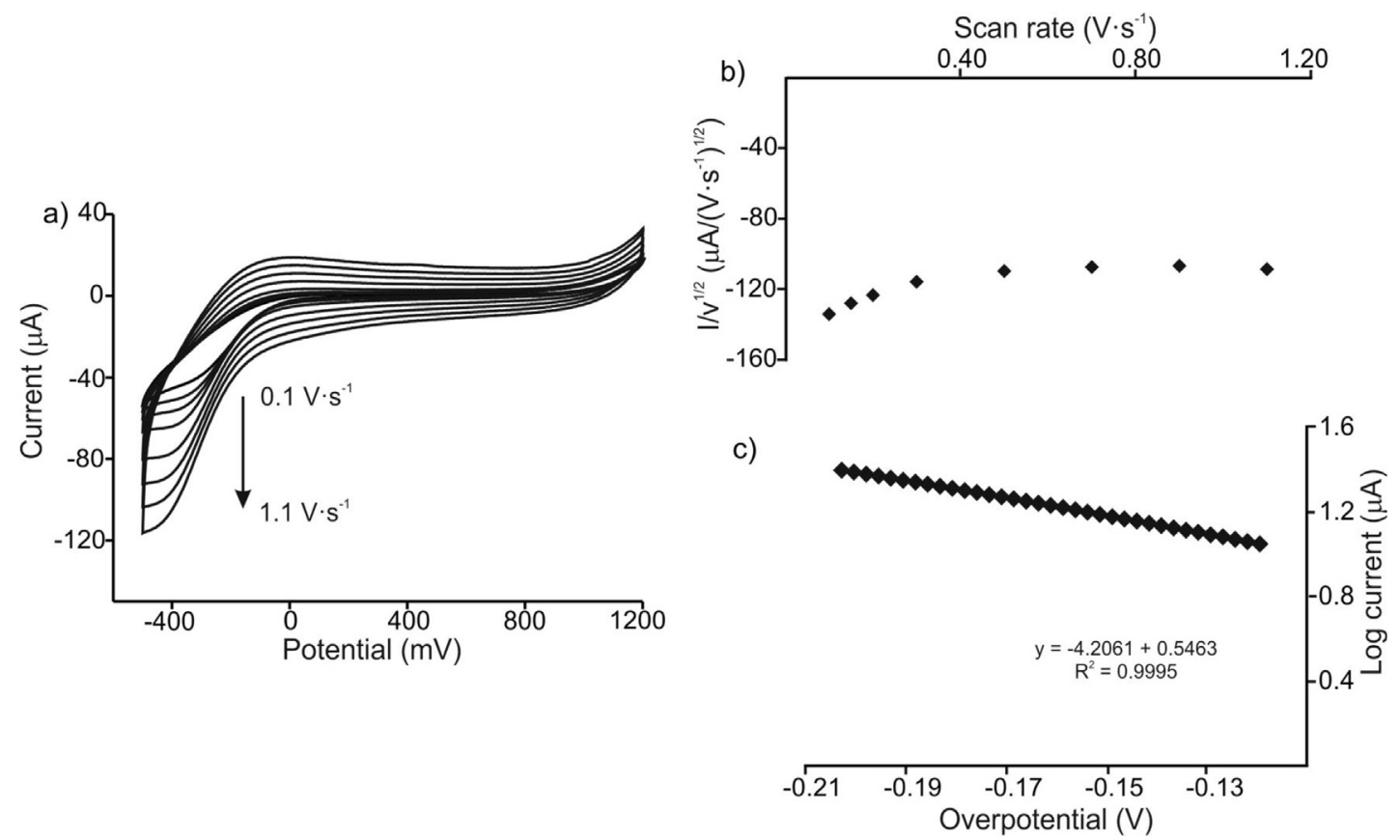

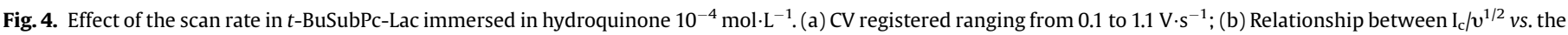
scan rate; (c) Tafel plot representing logarithm of the intensity vs. the overpotential. 
Table 3

Relationship with scan rate in biosensors immersed in catechol or hydroquinone $10^{-4} \mathrm{~mol} \cdot \mathrm{L}^{-1}$ calculated in the cathodic peak.

\begin{tabular}{|c|c|c|c|c|c|c|c|c|}
\hline \multicolumn{9}{|l|}{ Catechol } \\
\hline & \multicolumn{2}{|c|}{$\mathrm{I}_{\mathrm{c}}(\mu \mathrm{A}) v s . v^{1 / 2}(\mathrm{~V} / \mathrm{s})^{1 / 2}$} & \multicolumn{2}{|c|}{$\mathrm{E}_{\mathrm{c}}(\mathrm{V}) v s . \log v(\mathrm{~V} / \mathrm{s})$} & \multicolumn{4}{|c|}{ Log I $(\mu \mathrm{A})$ vs. $\eta(\mathrm{V})$} \\
\hline Biosensor & Slope & $\mathrm{R}^{2}$ & Tafel Slope & $\mathrm{R}^{2}$ & $\alpha \cdot n$ & Slope & $\mathrm{R}^{2}$ & $\mathrm{n}$ \\
\hline ClSubPc-Tyr & -43.52 & 0.994 & -0.15 & 0.999 & 0.40 & -2.64 & 0.999 & 2.59 \\
\hline$t$-BuSubPc-Tyr & -39.97 & 0.983 & -0.10 & 0.996 & 0.59 & -4.17 & 0.999 & 2.40 \\
\hline PhOSubPc-Tyr & -47.78 & 0.914 & -0.18 & 0.963 & 0.34 & -2.53 & 0.995 & 2.24 \\
\hline \multicolumn{9}{|l|}{ Hydroquinone } \\
\hline & \multicolumn{2}{|c|}{$\mathrm{I}_{\mathrm{c}}(\mu \mathrm{A}) v s \cdot v^{1 / 2}(\mathrm{~V} / \mathrm{s})^{1 / 2}$} & \multicolumn{2}{|c|}{$\mathrm{E}_{\mathrm{c}}(\mathrm{V}) v s . \log v(\mathrm{~V} / \mathrm{s})$} & & \multicolumn{3}{|c|}{$\log I(\mu \mathrm{A})$ vs. $\eta(\mathrm{V})$} \\
\hline Biosensor & Slope & $\mathrm{R}^{2}$ & Tafel Slope & $\mathrm{R}^{2}$ & $\alpha \cdot n$ & Slope & $\mathrm{R}^{2}$ & $\mathrm{n}$ \\
\hline ClSubPc-Lac & -81.46 & 0.998 & -0.12 & 0.953 & 0.48 & -3.56 & 0.984 & 2.19 \\
\hline$t$-BuSubPc-Lac & -94.75 & 0.997 & -0.11 & 0.986 & 0.57 & -4.21 & 0.999 & 2.28 \\
\hline PhOSubPc-Lac & -109.55 & 0.999 & -0.13 & 0.983 & 0.46 & -3.37 & 0.984 & 2.42 \\
\hline
\end{tabular}

$\left(8.314 \mathrm{~J} \cdot \mathrm{mol}^{-1} \cdot \mathrm{K}^{-1}\right), T$ is the temperature $(298 \mathrm{~K})$ and $F$ is Faraday's constant $\left(95,484.56 \mathrm{C} \cdot \mathrm{mol}^{-1}\right)$.

From the slope of the $E_{c} v s$. $\log v, \alpha \cdot n$ values between 0.34 and -0.69 were obtained (Table 3 ). These values are comparable to those reported for other phthalocyanines $[7,49]$.

The Tafel plot relate the rate of an electrochemical reaction to the overpotential and can give information about the ratedetermining step and the efficiency of a catalyst. Using the simplified Butler-Volmer's equation and representing Log I vs. the overpotential $(\eta)$ obtained from a voltammogram registered in catechol or hydroquinone $10^{-4} \mathrm{~mol} \cdot \mathrm{L}^{-1}$ at scan rate of $0.2 \mathrm{~V} \cdot \mathrm{s}^{-1}$ (Fig. 4c), $\alpha$ values were calculated (equation 2) [53].The number of electrons involved in the redox process can be calculated substituting the $\alpha$ values obtained from the Tafel plot in Laviron's equation. The calculated Tafel slopes, the $\alpha$ values and the number of electrons are listed in Table 3. The calculations agree well with an involvement of two-electron processes.

$\log I=\log _{0}-\frac{\alpha \cdot F}{2.3 \cdot R \cdot T} \eta$

The apparent Michaelis-Menten constant ( $\left.\mathrm{Km}^{\mathrm{app}}\right)$ was calculated from the electrochemical version of the Lineweaver-Burk equation to obtain information concerning the enzymatic affinity (equation 3).

$\frac{1}{I_{S}}=\frac{1}{I_{\max }}+\frac{\mathrm{Km}^{\mathrm{app}}}{I_{\max } \cdot \mathrm{C}}$

where $I_{s}$ is the steady current after the addition of the corresponding phenol and $I_{\max }$ is the maximum current measured under saturated substrate condition $\left(10^{-2} \mathrm{~mol} \cdot \mathrm{L}^{-1}\right)$. The $\mathrm{K}_{\mathrm{m}}{ }^{\text {app }}$ was determined from the slope and intercept for the calibration plot of reciprocals of current $v s$. catechol or hydroquinone concentration measured from $10^{-5}$ to $10^{-2} \mathrm{~mol} \cdot \mathrm{L}^{-1}$ (Table 4 ). In good accordance with LDs, the lowest $\mathrm{K}_{\mathrm{m}}{ }^{\text {app }}$ (higher affinity) was found using PhOSubPc, confirming the higher efficiency of the phenoxy derivative as an electron mediator.

Table 4

$\mathrm{K}_{\mathrm{m}}{ }^{\text {app }}$ calculated from Lineweaver-Burk equation.

\begin{tabular}{llll}
\hline SubPc-Tyr biosensor & $\mathrm{K}_{\mathrm{m}}{ }^{\text {app }}$ & SubPc-Lac biosensor & $\mathrm{K}_{\mathrm{m}}{ }^{\mathrm{app}}$ \\
\hline ClSubPc-Tyr & $8.7 \cdot 10^{-3}$ & ClSubPc-Lac & $1.73 \cdot 10^{-3}$ \\
PhOSubPc-Tyr & $1.9 \cdot 10^{-3}$ & PhOSubPc-Lac & $1.26 \cdot 10^{-4}$ \\
$t$-BuSubPc-Tyr & $4.0 \cdot 10^{-2}$ & $t$-BuSubPc-Lac & $2.06 \cdot 10^{-3}$ \\
\hline
\end{tabular}

\subsection{Reproducibility, repeatability and lifetime}

The reproducibility of the enzyme electrodes was investigated at a catechol or hydroquinone concentration of $1.10^{-4} \mathrm{~mol} \cdot \mathrm{L}^{-1}$ (sweep rate $0.1 \mathrm{~V} \cdot \mathrm{s}^{-1}$ ). In all cases, the first cycle was slightly different from the rest and was discarded. After that, biosensors were highly reproducible and, in 10 successive cycles, a small decrease of the signal was observed. Ten consecutive measurements showed variation coefficients (of the peak current at $-0.4 \mathrm{~V}$ ) lower than 3\% for measures in hydroquinone and lower than $6 \%$ for measures in catechol.

The reproducibility of three electrodes, independently fabricated, showed variation coefficients lower than $5 \%$ for the peak current at $-0.3 \mathrm{~V}$ in biosensors modified with laccase, and lower than $9 \%$ for biosensors modified with tyrosinase.

Sensors could be cycled up to 50 times with a loss of intensity lower than $11 \%$. However, once the sensors are withdrawn from the solution, a clear decrease in intensity of the peaks is observed. So, sensors can be considered as disposable.

\subsection{Exploring the application in the analysis of the Total Phenol Index (TPI) in wines}

The different behavior shown by the three subphthalocyanines could be used to construct a bioelectronic tongue. The possibility to discriminate real samples was explored using three red wines with a different Total Polyphenolic Index.

Fig. 5 illustrates the voltammetric responses obtained from the wines. Voltammograms showed redox peaks at positive potentials whose intensity depended on the type of sensor but also on the TPI of the analyzed wine. Thus, the intensity of the peaks increased with the TPI.

Principal Component Analysis (PCA) was used to evaluate the capability of the bioET to discriminate wines and musts according to the variety of grape. PCA scores plots for wines (Fig. 6) showed well-defined and separated clusters for each type of wine. The captured information was 99.9\% (PC1 =96.7\%; PC2 = 2.9\%; PC3 = $0.3 \%)$.

Clusters were distributed in the plot according to the TPI along PC2. Thus, wine 1 with the highest TPI values (76.7) appeared in the left part of the graph in the negative PC2 region. Wine 3 with the lowest TPI (58.9) was located in the right part of the graph in the PC2 positive region. Wine 2 with a high TPI but showing an intermediate value was located in an intermediate position. According to this result, the bioET based on sensors and biosensors containing SubPcs could be used to discriminate wines according to their phenolic content. 

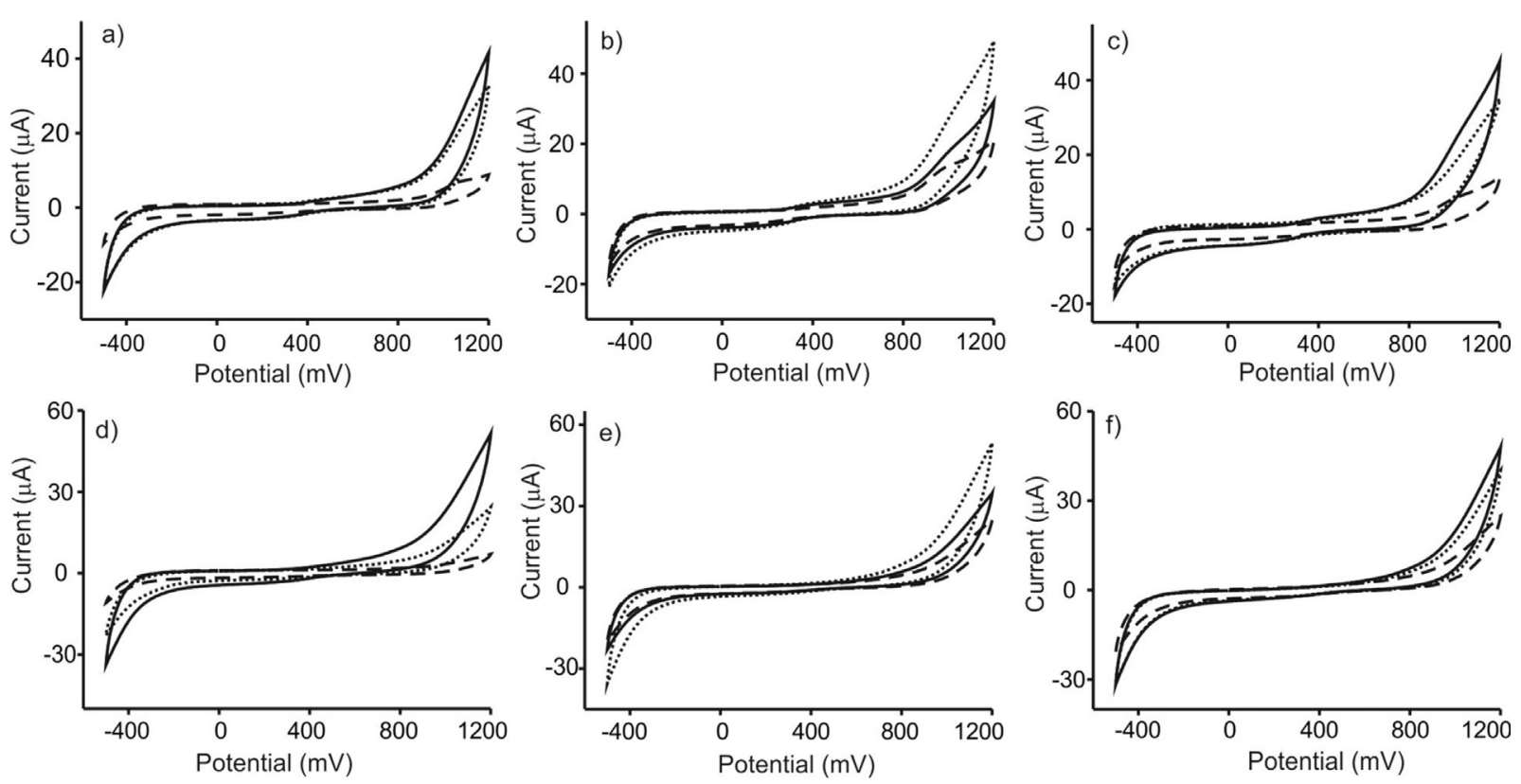

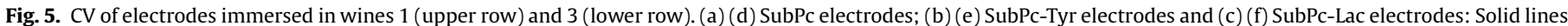
correspond to CISubPc based electrodes, dashed lines correspond to PhOSubPc based electrodes and dotted line correspond to $t$-BuSubPc based electrodes.

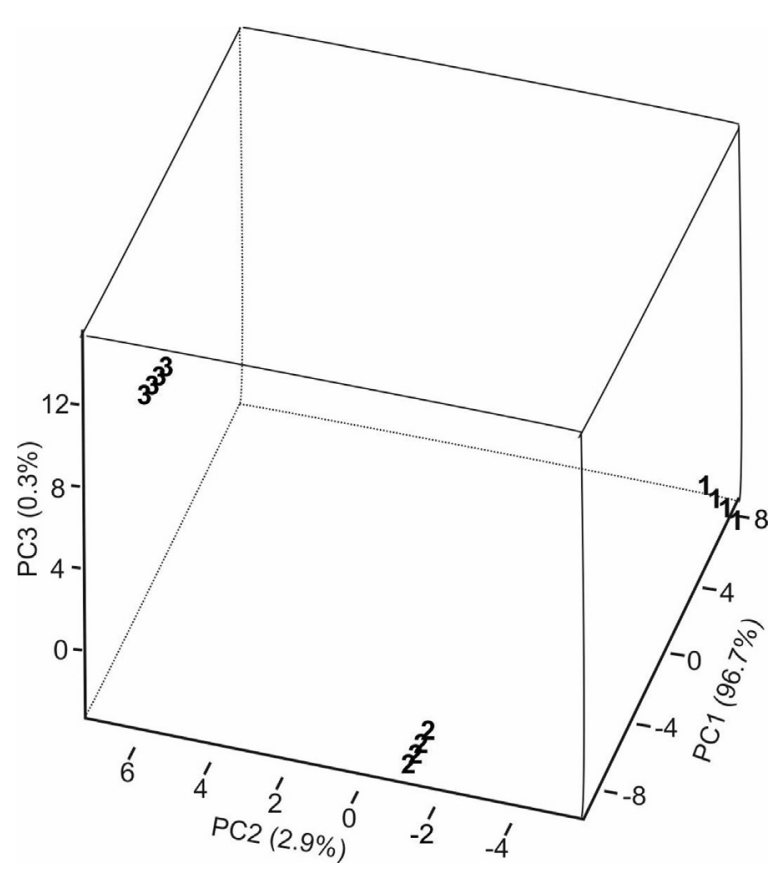

Fig. 6. 3D PCA score plots of the bioelectronic tongue obtained from voltammetric responses in wines.

\section{Conclusions}

This work demonstrates that subphthalocyanines are attractive electron mediators for phenol oxidases, promoting electron transfer between Tyrosinase or Laccase and the electrode. Limits of detection for catechol and hydroquinone are in the scale of $1 \cdot 10^{-7} \mathrm{~mol} \cdot \mathrm{L}^{-1}$ with linear ranges from $10^{-5} \mathrm{~mol} \cdot \mathrm{L}^{-1}$ to $10^{-7}$ $\mathrm{mol} \cdot \mathrm{L}^{-1}$, and high sensitivities.
Response characteristics are modulated by the peripheral substituents and are improved in the presence of phenoxy groups thanks to $\pi-\pi$ interactions between the aromatic rings of the SubPcs, and the enzymatic active sites. Studies at increasing scan rates, confirmed the improvement of the charge transfer rates caused by the presence of the SubPcs. The SubPc based sensors and biosensors have been used to obtain an array of sensors with a high degree of cross-selectivity. The bioelectronic tongue has been able to discriminate between red wines according to their Total Polyphenol Index.

\section{Acknowledgements}

We are grateful to the Russian Scientific Fund (Grant 17-1301197) for support of this research. MINECO-FEDER (AGL201567482-R) and the Junta de Castilla y León-FEDER (VA-032U13) are also acknowledged. Celia Garcia-Hernandez would also like to thank Junta de Castilla y León for a grant (BOCYL-D-4112015-9).

\section{References}

[1] O. Makhotkina, P.A. Kilmartin, The use of cyclic voltammetry for wine analysis: Determination of polyphenols and free sulfur dioxide, Anal. Chim. Acta. 668 (2010) 155-165, doi:http://dx.doi.org/10.1016/j.aca.2010.03.064.

[2] J. Cabaj, A. Jędrychowska, A. Świst, J. Sołoducho, Tyrosinase Biosensor for Antioxidants Based on Semiconducting Polymer Support, Electroanalysis 28 (2016) 1383-1390, doi:http://dx.doi.org/10.1002/elan.201500523.

[3] X. Cetó, C. Apetrei, M. del Valle, M.L. Rodríguez-Méndez, Evaluation of red wines antioxidant capacity by means of a voltammetric e-tongue with an optimized sensor array, Electrochim. Acta. 120 (2014) 180-186, doi:http://dx. doi.org/10.1016/j.electacta.2013.12.079.

[4] A. Gutés, F. Céspedes, S. Alegret, M. del Valle, Determination of phenolic compounds by a polyphenol oxidase amperometric biosensor and artificial neural network analysis, Biosens. Bioelectron. 20 (2005) 1668-1673, doi: http://dx.doi.org/10.1016/j.bios.2004.07.026.

[5] F. Karim, A.N.M. Fakhruddin, Recent advances in the development of biosensor for phenol: a review, Rev. Environ. Sci. Bio/Technology. 11 (2012) 261-274, doi: http://dx.doi.org/10.1007/s11157-012-9268-9.

[6] J.H. Zagal, S. Griveau, J.F. Silva, T. Nyokong, F. Bedioui, Metallophthalocyaninebased molecular materials as catalysts for electrochemical reactions, Coord. Chem. Rev. 254 (2010) 2755-2791, doi:http://dx.doi.org/10.1016/j. ccr.2010.05.001. 
[7] C. Medina-Plaza, L.N. Furini, C.J.L. Constantino, J.A. De Saja, M.L. RodríguezMéndez, Synergistic electrocatalytic effect of nanostructured mixed films formed by functionalised gold nanoparticles and bisphthalocyanines, (2014) .

[8] E.G.R. Fernandes, L.C. Brazaca, M.L. Rodríguez-Mendez, J.A. de Saja, V. Zucolotto, Immobilization of lutetium bisphthalocyanine in nanostructured biomimetic sensors using the LbL technique for phenol detection, Biosens. Bioelectron. 26 (2011) 4715-4719, doi:http://dx.doi.org/10.1016/j. bios.2011.05.032.

[9] M. Gay Martín, J.A. de Saja, R. Muñoz, M.L. Rodríguez-Méndez, Multisensor system based on bisphthalocyanine nanowires for the detection of antioxidants, Electrochim. Acta. 68 (2012) 88-94, doi:http://dx.doi.org/ 10.1016/j.electacta.2012.02.042.

[10] L. Cui, T. Pu, Y. Liu, X. He, Layer-by-layer construction of graphene/cobalt phthalocyanine composite film on activated GCE for application as a nitrite sensor, Electrochim. Acta. 88 (2013) 559-564, doi:http://dx.doi.org/10.1016/j. electacta.2012.10.127.

[11] K. Hou, L. Huang, Y. Qi, C. Huang, H. Pan, M. Du, A bisphenol A sensor based on novel self-assembly of zinc phthalocyanine tetrasulfonic acid-functionalized graphene nanocomposites, Mater. Sci. Eng. C. 49 (2015) 640-647, doi:http:// dx.doi.org/10.1016/j.msec.2015.01.064.

[12] M. Shumba, T. Nyokong, Electrocatalytic application for gold nanoparticles decorated sulfur-nitrogen co-doped graphene oxide nanosheets and nanosized cobalt tetra aminophenoxy phthalocyanine conjugates, Electrochim. Acta. 236 (2017) 212-220, doi:http://dx.doi.org/10.1016/j. electacta.2017.03.154.

[13] F.J. Pavinatto, E.G.R. Fernandes, P. Alessio, C.J.L. Constantino, J.A. de Saja, V. Zucolotto, C. Apetrei, O.N. Oliveira Jr, M.L. Rodriguez-Mendez, Optimized architecture for Tyrosinase-containing Langmuir?Blodgett films to detect pyrogallol, J. Mater. Chem 21 (2011) 4995, doi:http://dx.doi.org/10.1039/ c0jm03864d.

[14] H. Yin, Y. Zhou, S. Ai, Preparation and characteristic of cobalt phthalocyanine modified carbon paste electrode for bisphenol A detection, J. Electroanal. Chem. 626 (2009) 80-88, doi:http://dx.doi.org/10.1016/j. jelechem.2008.11.004.

[15] H. Yin, Y. Zhou, J. Xu, S. Ai, L. Cui, L. Zhu, Amperometric biosensor based on tyrosinase immobilized onto multiwalled carbon nanotubes-cobalt phthalocyanine-silk fibroin film and its application to determine bisphenol A, Anal. Chim. Acta. 659 (2010) 144-150, doi:http://dx.doi.org/10.1016/j. aca.2009.11.051.

[16] C.G. Claessens, D. González-Rodríguez, M.S. Rodríguez-Morgade, A. Medina, T. Torres, Subporphyrazines Subphthalocyanines, and Subporphyrins Singular Nonplanar Aromatic Systems, Chem. Rev. 114 (2014) 2192-2277, doi:http://dx. doi.org/10.1021/cr400088w.

[17] J. Rauschnabel, M. Hanack, New derivatives and homologues of subphthalocyanine, Tetrahedron Lett. 36 (1995) 1629-1632, doi:http://dx. doi.org/10.1016/0040-4039(95)00124-U.

[18] B. del Rey, T. Torres, Synthesis of Highly conjugated boron (III) subphthalocyanines, Tetrahedron Lett. 38 (1997) 5351-5354, doi:http://dx. doi.org/10.1016/S0040-4039(97)01170-2.

[19] A.Y. Tolbin, L.G. Tomilova, Subphthalocyanines and their analogues: methods for the synthesis and structure modification, Russ. Chem. Rev. 80 (2011) 531551, doi:http://dx.doi.org/10.1070/RC2011v080n06ABEH004198.

[20] T.V. Dubinina, M.M. Osipova, A.V. Zasedatelev, V.I. Krasovskii, N.E. Borisova, S. A. Trashin, L.G. Tomilova, N.S. Zefirov, Synthesis, optical and electrochemical properties of novel phenyl- and phenoxy-substituted subphthalocyanines, Dye. Pigment. 128 (2016) 141-148, doi:http://dx.doi.org/10.1016/j. dyepig.2016.01.023.

[21] M. Geyer, F. Plenzig, J. Rauschnabel, M. Hanack, B. del Rey, A. Sastre, T. Torres, Subphthalocyanines: Preparation, Reactivity and Physical Properties, Synthesis (Stuttg). 1996 (1996) 1139-1151, doi:http://dx.doi.org/10.1055/s1996-4349.

[22] S. Shimizu, A. Miura, S. Khene, T. Nyokong, N. Kobayashi, 1 Chiral, 2Subnaphthalocyanines, J. Am. Chem. Soc. 133 (2011) 17322-17328, doi:http:// dx.doi.org/10.1021/ja2052667.

[23] G.G. Dubinina, M.M. Zakirova, E.F. Osipova, Novel phenoxy-substituted subphthalocyanines possessing an extended $\pi$-system: synthesis and property investigation, Russ. Chem Bull . 64 (2015) 2253-2256, doi:http://dx. doi.org/10.1007/s11172-015-1147-4.

[24] Y. Takao, T. Masuoka, K. Yamamoto, T. Mizutani, F. Matsumoto, K. Moriwaki, K. Hida, T. Iwai, T. Ito, T. Mizuno, T. Ohno, Synthesis and properties of novel fluorinated subnaphthalocyanines for organic photovoltaic cells, (2014), doi: http://dx.doi.org/10.1016/j.tetlet.2014.06.069.

[25] H. Zhu, S. Shimizu, N. Kobayashi, Subazaphenalenephthalocyanine A Subphthalocyanine Analogue Bearing a Six-Membered Ring Unit, Angew. Chemie Int. Ed. 49 (2010) 8000-8003, doi:http://dx.doi.org/10.1002/ anie.201003929.

[26] T. Fukuda, J.R. Stork, R.J. Potucek, M.M. Olmstead, B.C. Noll, N. Kobayashi, W.S Durfee, cis andtrans Forms of a Binuclear Subphthalocyanine, Angew. Chemie Int. Ed. 41 (2002) 2565-2568, doi:http://dx.doi.org/10.1002/1521-3773 (20020715)41:14<2565:AID-ANIE2565>3.0.CO;2-G.

[27] R.S. Iglesias, C.G. Claessens, T. Torres, Herranz M.Á, V.R. Ferro, J.M. García De La Vega, Subphthalocyanine-fused dimers and trimers: Synthetic, electrochemical, and theoretical studies, J. Org. Chem. 72 (2007) 2967-2977, doi:http://dx.doi.org/10.1021/jo062608h.
[28] G.E. Morse, T.P. Bender, Boron Subphthalocyanines as Organic Electronic Materials, ACS Appl, Mater. Interfaces. 4 (2012) 5055-5068, doi:http://dx.doi. org/10.1021/am3015197.

[29] K. Cnops, B.P. Rand, D. Cheyns, B. Verreet, M.A. Empl, P. Heremans, 8.4\% efficient fullerene-free organic solar cells exploiting long-range exciton energy transfer, Nat. Commun. 5 (2014) 53711, doi:http://dx.doi.org/10.1038/ ncomms4406

[30] C.-F. Lin, S.-W. Liu, C.-C. Lee, J.-C. Hunag, W.-C. Su, T.-L. Chiu, C.-T. Chen, J.-H. Lee, Open-circuit voltage and efficiency improvement of subphthalocyaninebased organic photovoltaic device through deposition rate control, Sol. Energy Mater. Sol. Cells. 103 (2012) 69-75, doi:http://dx.doi.org/10.1016/j. solmat.2012.04.005

[31] B. Verreet, B.P. Rand, D. Cheyns, A. Hadipour, T. Aernouts, P. Heremans, A. Medina, C.G. Claessens, T. Torres, A 4\% Efficient Organic Solar Cell Using a Fluorinated Fused Subphthalocyanine Dimer as an Electron Acceptor, Adv Energy Mater. 1 (2011) 565-568, doi:http://dx.doi.org/10.1002/ aenm.201100137.

[32] S.S. Maklakov, T.V. Dubinina, M.M. Osipova, E.F. Petrusevich, A.D. Mishin, L.C. Tomilova, A novel hybrid blend based on phenoxy-substituted boron subphthalocyanine for organic photodetectors, J. Porphyr. Phthalocyanines. 20 (2016) 1134-1141, doi:http://dx.doi.org/10.1142/S1088424616500759.

[33] N.V. Shvedene, K.N. Otkidach, E.E. Ondar, M.M. Osipova, T.V. Dubinina, L.G. Tomilova, I.V. Pletnev, Phenoxy-substituted boron subphthalocyanine as a ionophore of ion-selective electrodes, J. Anal. Chem. 72 (2017) 95-104, doi: http://dx.doi.org/10.1134/S1061934817010117.

[34] F.M.F. Roleira, E.J. Tavares-da-Silva, C.L. Varela, S.C. Costa, T. Silva, J. Garrido, F. Borges, Plant derived and dietary phenolic antioxidants: Anticancer properties, Food Chem. 183 (2015) 235-258, doi:http://dx.doi.org/10.1016/j. foodchem.2015.03.039.

[35] M.L.R. Mendez, Electronic noses and tongues in food science, Academic Press, 2016.

[36] M.L. Rodriguez-Mendez, C. Apetrei, M. Gay, C. Medina-Plaza, J.A. De Saja, S. Vidal, O. Aagaard, M. Ugliano, J. Wirth, V. Cheynier, Evaluation of oxygen exposure levels and polyphenolic content of red wines using an electronic panel formed by an electronic nose and an electronic tongue, Food Chem. 155 (2014), doi:http://dx.doi.org/10.1016/j.foodchem.2014.01.021.

[37] N.V. Pradeep, S. Anupama, K. Navya, H.N. Shalini, M. Idris, U.S. Hampannavar Biological removal of phenol from wastewaters: a mini review, Appl. Water Sci. 5 (2015) 105-112, doi:http://dx.doi.org/10.1007/s13201-014-0176-8.

[38] E.G. McRae, M. Kasha, The Molecular Exciton Model, Phys. Process. Radiat. Biol, Elsevier, 1964, pp. 23-42, doi:http://dx.doi.org/10.1016/B978-1-4831-98248.50007-4.

[39] N. Prieto, M. Gay, S. Vidal, O. Aagaard, J.A. De Saja, M.L. Rodriguez-Mendez, Analysis of the influence of the type of closure in the organoleptic characteristics of a red wine by using an electronic panel, Food Chem. 129 (2011), doi:http://dx.doi.org/10.1016/j.foodchem.2011.04.071.

[40] Christian G. Claessens, A. David González-Rodríguez, T. Torres*, Subphthalocyanines Singular Nonplanar Aromatic Compounds-Synthesis, Reactivity, and Physical Properties, Chem. Rev. 102 (2002) 835-854, doi:http:// dx.doi.org/10.1021/CR0101454.

[41] J. Adamski, P. Nowak, J. Kochana, Simple sensor for the determination of phenol and its derivatives in water based on enzyme tyrosinase, Electrochim. Acta. 55 (2010) 2363-2367, doi:http://dx.doi.org/10.1016/j. electacta.2009.11.099.

[42] C. Medina-Plaza, J.A. De Saja, M.L. Rodriguez-Mendez, Bioelectronic tongue based on lipidic nanostructured layers containing phenol oxidases and lutetium bisphthalocyanine for the analysis of grapes, Biosens. Bioelectron. 57 (2014) 276-283, doi:http://dx.doi.org/10.1016/j.bios.2014.02.023.

[43] M. Portaccio, D. Di Tuoro, F. Arduini, D. Moscone, M. Cammarota, D.G. Mita, M. Lepore, Laccase biosensor based on screen-printed electrode modified with thionine?carbon black nanocomposite, for Bisphenol A detection, Electrochim. Acta. 109 (2013) 340-347, doi:http://dx.doi.org/10.1016/j. electacta.2013.07.129.

[44] C. Medina-Plaza, L.N. Furini, C.J.L. Constantino, J.A. de Saja, M.L. RodriguezMendez, Synergistic electrocatalytic effect of nanostructured mixed films formed by functionalised gold nanoparticles and bisphthalocyanines, Anal. Chim. Acta. 851 (2014) 95-102, doi:http://dx.doi.org/10.1016/j. aca.2014.08.049.

[45] M. Buleandra, A.A. Rabinca, I.A. Badea, A. Balan, I. Stamatin, C. Mihailciuc, A.A. Ciucu, Voltammetric determination of dihydroxybenzene isomers using a disposable pencil graphite electrode modified with cobalt-phthalocyanine, Microchim. Acta. 184 (2017) 1481-1488, doi:http://dx.doi.org/10.1007/ s00604-017-2153-z.

[46] M.D. Maximino, C.S. Martin, F.V. Paulovich, P. Alessio, Layer-by-Layer Thin Film of Iron Phthalocyanine as a Simple and Fast Sensor for Polyphenol Determination in Tea Samples, J. Food Sci. 81 (2016) C2344-C2351, doi:http:// dx.doi.org/10.1111/1750-3841.13394.

[47] M.L. Rodríguez-Méndez, C. Medina-Plaza, C. García-Hernández, S. Rodríguez, C. García-Cabezón, D. Paniagua, M.A. Rodríguez-Pérez, J.A. De Saja, Improvement of electrocatalytic effect in voltammetric sensors based on phthalocyanines, J. Porphyr. Phthalocyanines. 20 (2016), doi:http://dx.doi.org/ $10.1142 /$ S1088424616500218

[48] S.M. Silva, F.M. de Oliveira, D.D. Justino, L.T. Kubota, A.A. Tanaka, F.S. Damos, R. de Cássia Silva Luz, A Novel Sensor Based on Manganese azo-Macrocycle/ Carbon Nanotubes to Perform the Oxidation and Reduction Processes of Two 
Diphenol Isomers, Electroanalysis 26 (2014) 602-611, doi:http://dx.doi.org/ 10.1002/elan.201300576.

[49] F. Matemadombo, C. Apetrei, T. Nyokong, M.L. Rodríguez-Méndez, J.A. de Saja, Comparison of carbon screen-printed and disk electrodes in the detection of antioxidants using CoPc derivatives, Sensors Actuators B Chem. 166-167 (2012) 457-466, doi:http://dx.doi.org/10.1016/j.snb.2012.02.088.

[50] P. Alessio, F.J. Pavinatto, O.N. Oliveira, J.A. de Saja, C.J. Constantino, M.L. Rodriguez Mendez, Detection of catechol using mixed Langmuir-Blodgett films of a phospholipid and phthalocyanines as voltammetric sensors, Analyst 135 (2010) 2591-2599, doi:http://dx.doi.org/10.1039/c0an00159g.
[51] Q. Li, X. Liu, Polarographic behaviour of antiepilepsirine and its application, Anal. Chim. Acta. 258 (1992) 171-175, doi:http://dx.doi.org/10.1016/00032670(92)85211-N.

[52] A. Bard, L. Faulkner, Fundamentals and Electrochem applications Methods, (2001).

[53] J. Zhang, J. Xu, Y. Wen, Z. Wang, H. Zhang, W. Ding, Voltammetric determination of phytoinhibitor maleic hydrazide using PEDOT:PSS composite electrode, J. Electroanal. Chem. 751 (2015) 65-74, doi:http://dx.doi. org/10.1016/j.jelechem.2015.05.032. 